\title{
FACTORY HOUSING. MAKING THE CONNECTIONS
}

\author{
Dr. Robert D. Wing \\ Department of Civil and Environmental Engineering, \\ Imperial College of Science, Technology and Medicine, \\ South Kensington, \\ London SW7 2BU. \\ r.wing@ic.ac.uk
}

\begin{abstract}
The global shortage of quality housing, with governments pushing expansion of their house-building programmes, points to an opportunity for the development of factory housing systems and the effective use of prefabrication. In recent years, numerous construction companies have experimented with the use of off-site production for housing, most of them resulting no significant cost-savings. This paper proposes that the changes required are not trivial, requiring a total rethink of conventional practices in order to arrive at effective automated systems. The building systems themselves need to be reconsidered in terms of factory automation, but the implications involve all aspects of the construction process from customer input, choice of ma terials, transport, use of I.T. tools, through to the details of connections.
\end{abstract}

Keywords: Prefabrication, housing, steel framed, extrusions, automation, connectors.

\section{Housing for the $21^{\text {st }}$ Century}

Prototype designs for future housing were to be seen this year at the Kitchen and Bath Industry Show, Chicago (April 2000). The 'house' was, however, on wheels.

Through collaboration with the Ford Motor Company, Maytag Appliances introduced a concept vehicle that they consider to be "personalised for individual lifestyles'.

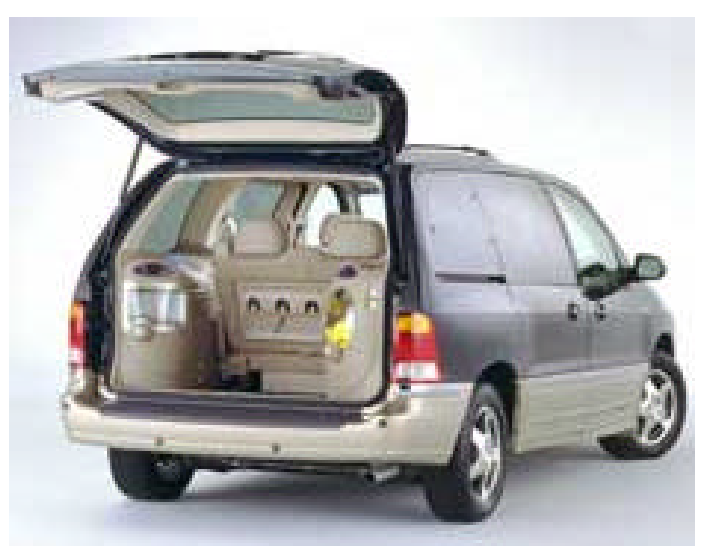

Figure 1. Custom-designed Maytag and Hoover products integrated into a 2000 Ford Windstar production minivan.
The "Windstar Solutions" vehicle, based on an existing minivan design, brought together Ford's engineering, technology, and safety teams with innovative products from Maytag and Hoover.

The Windstar contains two refrigerators, providing storage for drinks and perishable items, hot and cold cup holders, a microwave, a trash compactor, a combination washer/dryer, and a wet/dry utility vacuum.

Earlier this year at the Detroit International Automobile Show, (January 2000) Ford introduced another concept vehicle, the 24.7 cyber concept car.

Based again on an existing design, this vehicle is equipped with voice activated I.T. and communications facilities to keep the occupants in touch 24 hours a day through a dashboard that is almost entirely computer screen.

The system, developed by Ford's Visteon Automotive Systems parts subsidiary, responds to voice commands, and is capable of reconfiguring its functions to suit different drivers. One can call up a personal pre-selected arrangement of pictures, dashboard colours or music. Occupants can also ask the screen for a map to a destination or have the computer call home. Ev entually, the 24.7 will offer full voice-activated Web connections. 


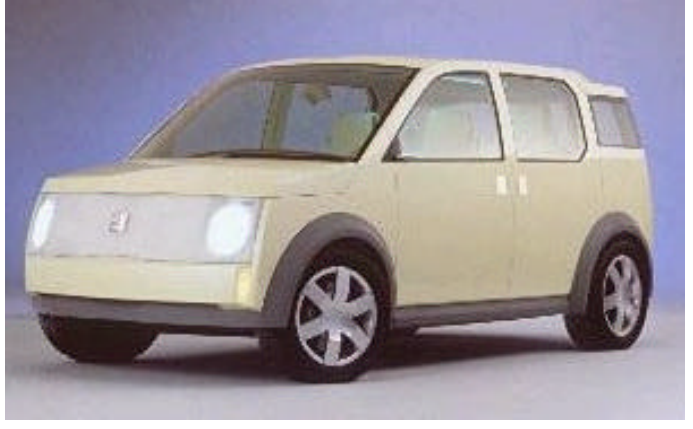

Figure 2. Ford 24.7 concept wagon, a sport utility vehicale featuring advanced voice technology and an instrument panel projecting custom layouts for each driver.

Between them, these two concept cars offer (apart from shower and bathroom) virtually all of the technical functionality that today's users should be demanding of the modern home.

They have progressed closer to Le Corbusier's vision of the 'Machine for Living' than the construction industry has dared to go, and while the similarities and differences of car and housing production have been extensively discussed (Gann, 1996) the lack of automation and I.T. facilities both in the housing product itself and in the building of it is difficult to understand.

Recognising that future housing solutions are likely to be factory based, the challenge for the construction industry is identical to that identified by Ford Motor Co. in providing a product that can be personalized to the consumer's lifestyle. In housing terms this requires a combination of flexible space provision and services that can grow as the new I.T.

technologies progress. Six themes can be identified as leading issues for housing in the immediate future (in no particular order):

- Provision of flexible space

- Expandable service provisions

- Energy efficiency

- Planned maintenance

- Environmentally healthy

- Affordable high quality

Modular housing, using a fully pre-fabricated factory build approach, can meet all of these objectives in a cost-efficient manner. The technologies demonstrated by Ford indicate that no technical barriers exist in the introduction of 'high-tech' customised factory housing in a cost-effective way. Construction companies are developing a number of solutions; some of these are discussed below, noting the remaining technical challenges, especially those concerning automation of the house-building process.

\section{Modular housing solutions.}

The development of truly modular housing that is capable of customization lies in finding solutions to three design choices:

- the level of prefabrication

a the materials

$\square$ and the connections.

These are all fundamental to the building system itself, also to the site delivery and assembly logistics. The economic argume nts in making these choices will not follow conventional industry experience. One of the early results arising from the motor industry was a list of principles to achieve Design for automation, the most relevant of which were:

- manual assembly costs will always tend to rise, whilst component fabrication costs will fall in relative terms (in the housing sector, build price is generally reckoned as $50 \%$ material cost and 50\% labour (Bolton et al, 1999)).

Integration of components should be sought, as this normally reduces the product cost. In design, the combination of adjacent components should always be considered; this can simplify the resulting assembly as well as reduce cost.

- Reduction in manual assembly work will generally have a bigger impact on reducing product cost than any increase in the cost of manufacture. Despite the capital cost of automation equipment, savings may be expected from reduced inter-process handling and improved product quality.

The level of prefabrication can be considered as the determining factor in deciding the division of labour between site and factory. One, two, and three dimensional approaches to prefabrication are all valid in this scenario, and serve to categorise some of the most promising modular methods, which are discussed below.

Papers presented at earlier IAARC conferences have debated the problems of component transport and assembly, recognizing that robots and automation devices for construction could not have the same stiffness as equipment used in other engine ering sectors. This presents a problem in heavy construction processes, but in housing, where the use of lightweight materials is acceptable, the scope for automation in both production and site assembly has widened. 


\section{Modular building systems and their potential for automation.}

Many of the materials now commonly used in the bulk of housing construction, including timber and $\mathrm{RC}$ (reinforced concrete) panel construction are likely to be overtaken by alternatives, despite their higher cost, as in an au tomation scenario the advantages in assembly and delivery will lead to more cost-effective processes. Timber frame and concrete would seem to be ideal contenders for factory automation, but factors that have previously been less significant in traditional housebuilding, such as dimensional accuracy and transport constraints, will open the way for other options.

Many pilot projects are currently under way, as the industry experiments with the possibilities of prefabrication. Modular build and panel technologies are not widespread in the industry, thus the implications for most house-builders involve a total rethink of their building systems. This represents a serious barrier to change in an industry that historically has dealt with change in an incremental rather than step manner.

In the following survey of current innovative projects, steel, aluminium, lightweight concrete, and glass reinforced plastics are proposed as the construction materials for the future factory -housing scene.

\subsection{Hot-rolled steel framing}

Hot rolled steel frames are used by several Japanese modular housing companies as the substantial framing provides inherent earthquake protection. The frames are welded into 3D room sized units, limited in size by transport considerations, and produced to high accuracy, typically $\pm 1 \mathrm{~mm}$ overall. The high accuracy permits simple factory assembly of the fit-out components, which are effected by a combination of automation tools and manual workers. The final product is of high quality, and is quic kly assembled on site with conventional equipment.

Modular housing systems such as these can reduce the cost and time of construction and provide tight quality control. This can deliver housing with zero defects on-site, removing the need for expensive and time-consuming 'snagging' and 'making good' (Egan,1998).

Cost savings are not reported, however, and there appears to be little scope for further automation of the processes.

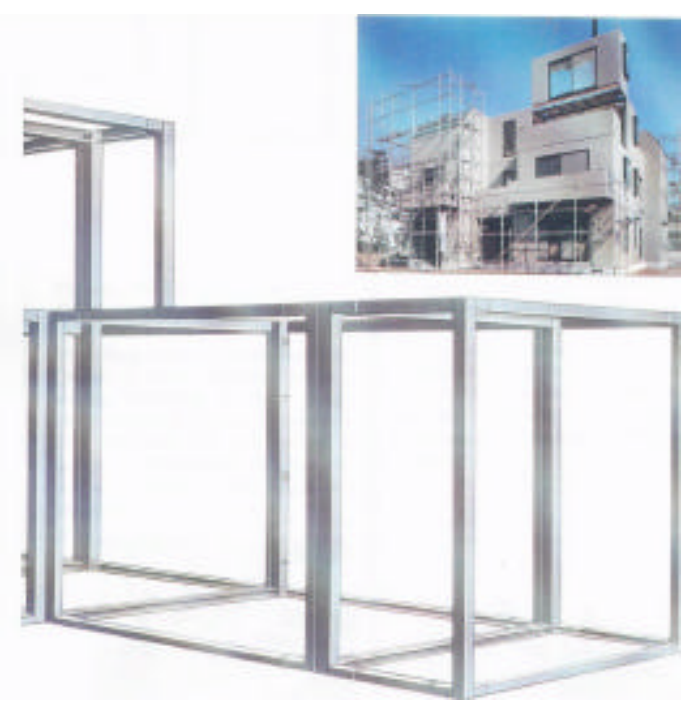

Figure 3. Sekisui steel framed housing system (Japan).

The same method is used outside Japan, especially for hotels and light industrial buildings, a good example being the modular McDonalds restaurants produced by two companies in the UK. These standardised units are completely fitted out in the factory, and site assembly can take as little as 24 hours.

One of these companies has extended the method to low-rise apartment buildings, where two modules are used for each dwelling. The pilot project in East London ran over budget due to extended site finishing works, but savings are expected with subsequent use of the method, and further projects are already in progress.

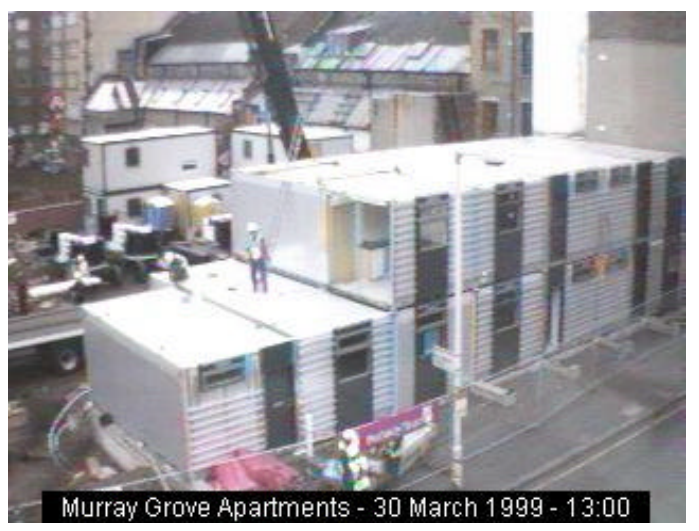

Fig 4. Murray Grove modular housing project under construction.

The author sees this approach as unlikely to produce substantial cost savings; its ess ential benefit is that it brings most of the construction work indoors, allowing all-weather working. There is too little use of automation within the factory, however, and much of the finishing work is left for completion on-site. 


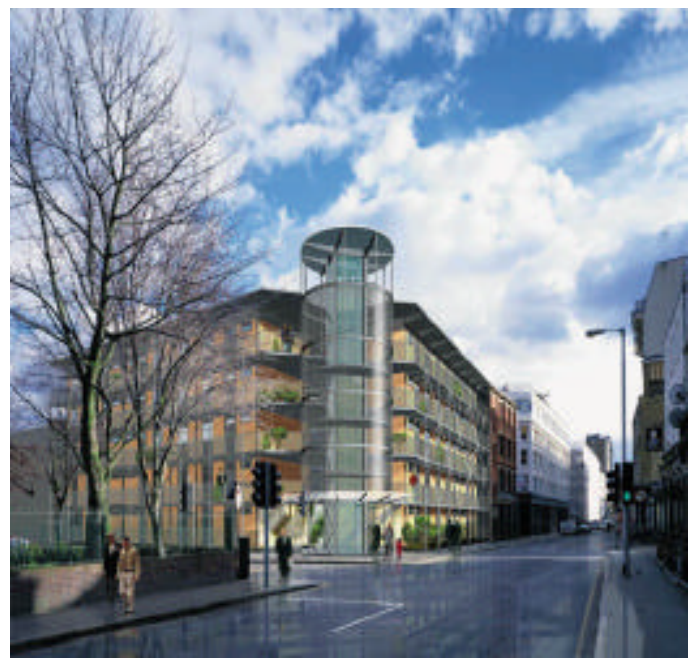

Fig 5. Murray Grove modular housing project visualization.

It is interesting to note that the driving force behind this development is the client, a major UK housing trust. For those of us who have been involved for some years in the introduction of automation and robotics in construction, it is encouraging to see that we are now entering a period of performance driven architecture and engineering, pushed by the demands of clients. The active participation of our clients is the only structure that will bring exploitation of the innovations we are creating. Let us hope that the new millennium sees the answer to Chris Wise's plea, "Please will our clients get their hands dirty and deliver something to us [engineers]; more leadership, less management" (Wise,2000).

\subsection{Light steel framing.}

The use of cold-rolled steel sections has become well established in North American house-building, where steel is frequently used as a direct substitute for timber. The 'stick' construction method may be used in all three dimensional approaches -

- $\quad$ delivered to site as pre-cut and punched 1D sticks which are rapidly assembled on site using manual connectors such as bolts, rivets, or selftapping screws.

- delivered on site as 2D subframes which have been factory assembled using welding or pressjoining.

- delivered on site as 3D modular units that may be completely finished in the factory, including carpets and fittings.

The $2 \mathrm{D}$ and $3 \mathrm{D}$ approaches may also integrate the stick components with sheet steel (or other sheet material) as backing to provide watertightness and improved structural stability. This 'cassette' method generally includes thermal insulation as an infill layer, and by extending the layer concept to include ducts for services, the wall panel develops into a fully prefabricated component designed to minimise site work.

At this point, the factory-site division becomes difficult, as customer preference may dictate a handbuilt façade, which would tend to negate any cost savings from factory prefabrication.

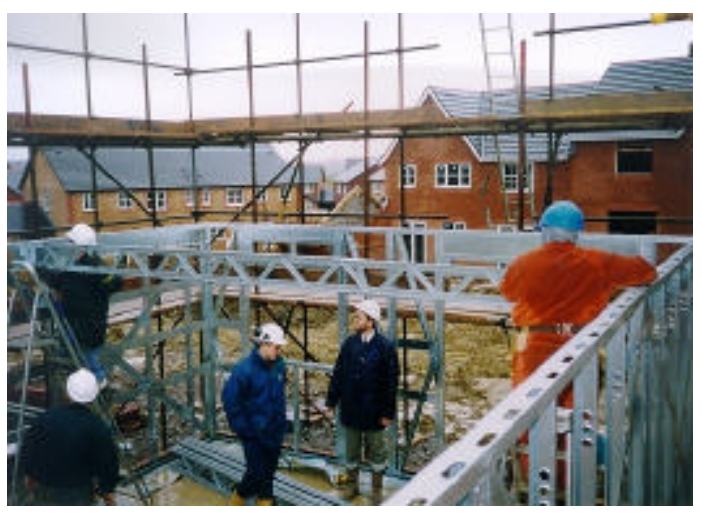

Fig 6. 'Surebuild' (Corus, UK) welded framing system.

New materials provide the most promising way forward for light steel framing systems. The 'Atmosfair' system uses lightweight concrete with expanded polystyrene aggregate to reduce the weight of panels. The balance of structural steel, thermal insulating layer, and lightweight concrete infill may be varied to produce required thermal, acoustic, and structural properties of individual panels.

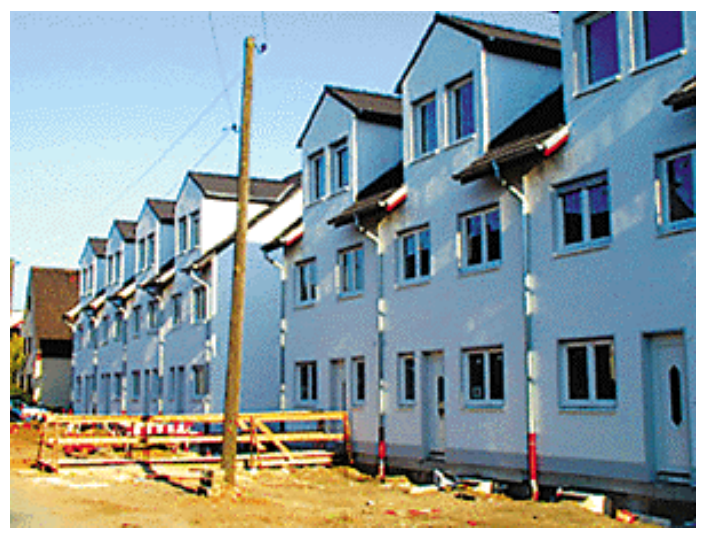

Figure 7. Atmosfair housing system (Germany).

The production system uses automation on automobile factory principles, and with no prefabricated elements weighing over $5 t$, site assembly can be rapidly effected using conventional equipment (Hohlsiepe,2000).

Attention has been paid to the inter-component connection details, the key to efficient site assembly. 


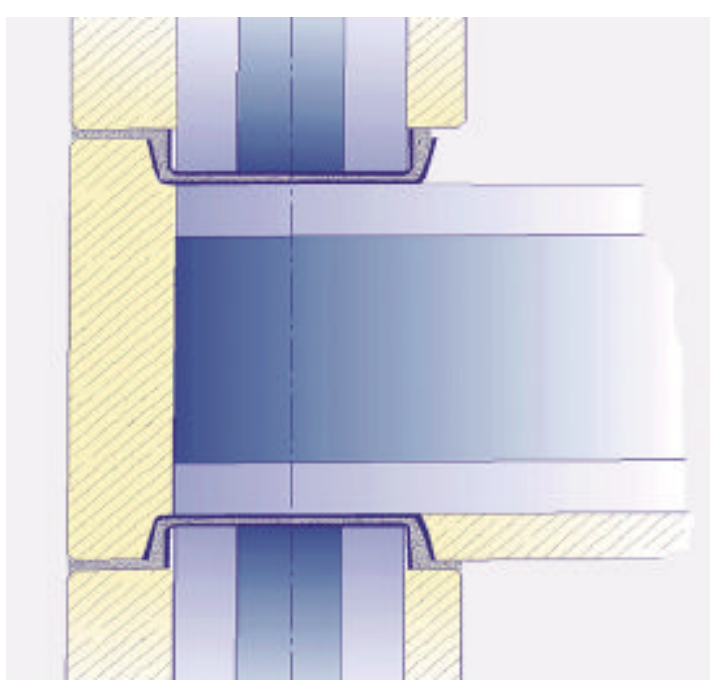

Figure 8. Detail of Atmosfair wall panel-floor connector.

Atmosfair claims a cost reduction of up to $30 \%$ in the building shell construction, and a site assembly time of less than 24 hours per house shell (excluding fitting out and installation of services).

The EU project FutureHome, which involves two major steel producers amongst its partners, is a study of the optimum factory -site division and of the automation and I.T. tools required to realise cost efficient production of quality homes (Atkin and Wing, 1999). Connectors and materials are leading engineering themes in this study, in which it is considered essential to provide choice not only for clients' preferences, but also to match local availability.

Although light steel framing is the chosen structural option, panels in any of the material discussed in this paper should be possible, with connectors capable of adapting to such variety. The connectors must be suited to automated assembly, and coupled with their structural, seismic, and other requirements, probably represent the major design challenge.

\subsection{Extruded structural materials.}

The quest for lightweight construction materials suggests various plastics and synthetics. From a structural viewpoint, however, the lack of test data and experience excludes many from consideration, as apart from the two following cases, they fall outside established building codes.

Extruded aluminium alloy has found extensive application in façade engineering, and there have been several attempts to extend its use into house construction. The buildings here are all monocoque cellular structures. Two concepts exist, the first employing aircraft fuselage structures as tubular house sections. A notable example of this approach is Kajima's concept apartments designed by Scott Howe (Howe, 1999).

The concept fulfills many automated production and assembly targets, and the same system could be realised with materials other than aluminium. There is, however, considerable architectural inflexibility.

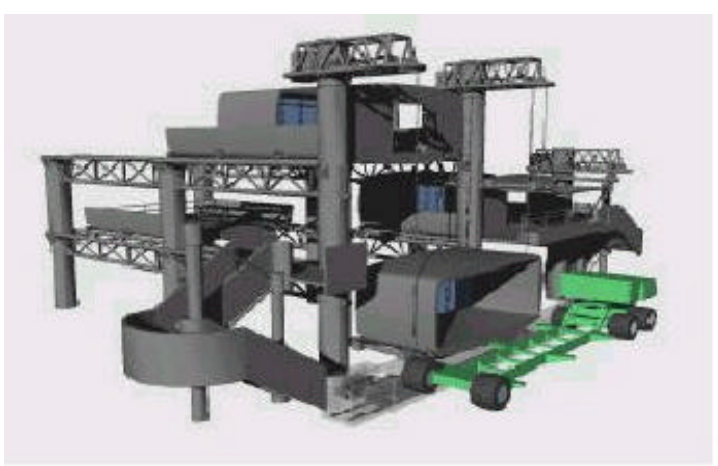

Figure 9. Kajima apartment system in aluminium alloy.

The second concept is firmly based on façade engineering, and uses very large aluminium extruded sections to make up floor and wall modules. The resulting structure is thereby extremely light, and the objective of the designers, E.U.Haus, is to produce a complete apartment including all insulation materials, services, etc. within a weight limit of 25t, the maximum load capacity of large helicopters. Site works are seen as simply the ground slab preparation with service sockets ready to connect instantly to the air-delivered house.

Jointing and sealing between the large aluminium cellular sections uses extruded plastic strips as are common in aluminium façades, these strips matching the undercut channels in the metal profiles to provide semi-rigid joints.

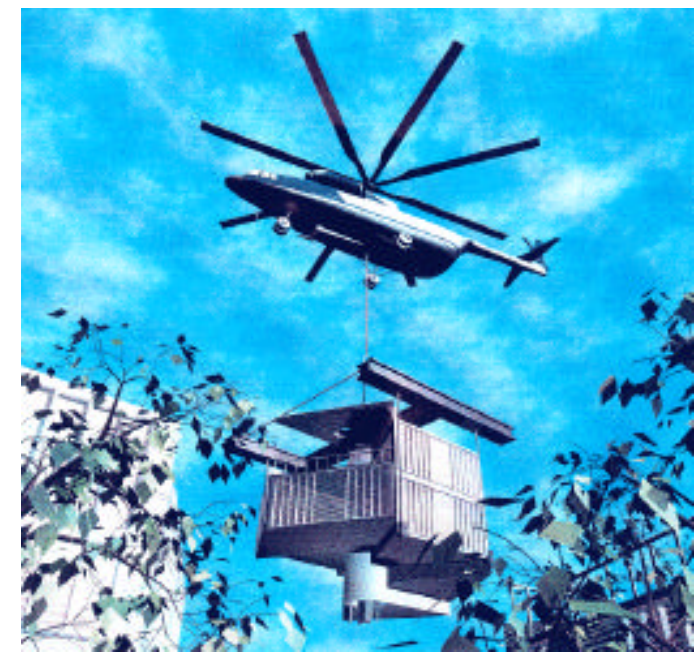

Figure 10. E.U.Haus (Germany) concept for lightweight apartment in aluminium alloy extruded materials. 
The sections themselves can include pipe cutouts for services, water supply, central heating, etc., and permits thermal insulation to be injected within the profile.

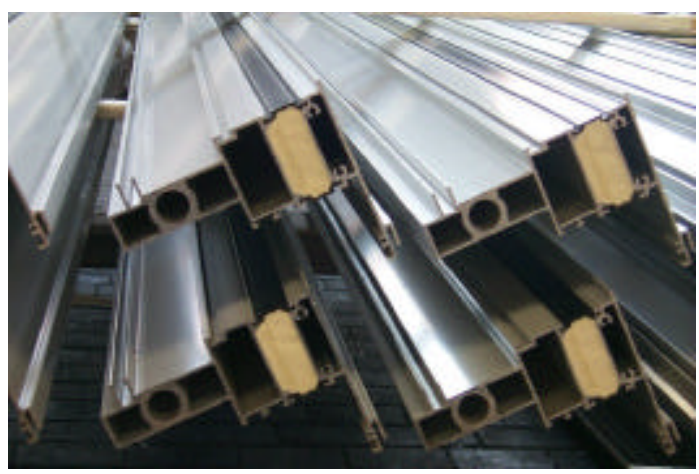

Figure 11. Typical aluminium alloy profiles with pipe channels, thermal insulation filling, and edge connector profiling.

A further material produced by extrusion, or more precisely by pultrusion, is the glass fibre - polyester resin material used in the patented Advanced Composite Construction System (ACCS) by Maunsell. The properties of this material are well known, following extensive testing and its use in a number of construction projects including bridge decks and light industrial buildings.

The system is based on a number of standard interlocking extrusions, which can be combined to produce deck and shell structures. The connector challenge is addressed in the components kit, and thermal and acoustic requirements can, as with the aluminium system, be met by filling the cellular sections with appropriate insulating materials.

\begin{tabular}{|c|c|c|}
\hline Shape & $\begin{array}{c}\text { Component } \\
\text { name }\end{array}$ & $\begin{array}{c}\text { Overall } \\
\text { dimensions }\end{array}$ \\
\hline 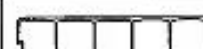 & Plank & $600 \times 80 \mathrm{~mm}$ \\
\hline & $\begin{array}{l}\text { 3-way } \\
\text { connector }\end{array}$ & $80 \times 80 \mathrm{~mm}$ \\
\hline$\sqrt{9}$ & $\begin{array}{l}\text { Groove } \\
\text { connector }\end{array}$ & $60 \times 80 \mathrm{~mm}$ \\
\hline$b$ & $\begin{array}{l}\text { Toggle } \\
\text { connector }\end{array}$ & $15.4 \times 20 \mathrm{~mm}$ \\
\hline & End Trimmer & $120 \times 130 \mathrm{~mm}$ \\
\hline
\end{tabular}

Figure 12. Maunsell (UK) basic range of ACCS components.

\section{Conclusions.}

House-builders are entering a period of challenge, as competitive methods based on factory automation evolve, and as clients' demands for performancedriven architecture and engineering begin to lead the market. Demands driven by energy and sustainability issues will also play a part in this evolution, resulting in housing products very different from the traditional.

Those involved in automation and robotics should see this as an entry point for the construction industry that will require considerable $R \& D$ effort.

\section{Acknowledgements}

The author wishes to acknowledge the support of the European Commission through IMS-Brite Euram contract BRPR-CT98-9004 for this study.

\section{References}

Atkin, B.L and Wing, R.D.,'FutureHomeManufa ctured Housing for Europe', $16^{\text {th }}$ International Symposium on Automation and Robotics in Construction, Madrid, Sept. 1999. pp.573-578.

Bolton, G., Geeson, P., Lyle, J., and Miles, J.C.,'Housing: an exercise in industrial design', The Arup Journal, 3/1999.

Egan, J.,'Rethinking Construction', UK Dept.of the Environment, Transport and the Regions. 1998. www.construction.detr.gov.uk/cis/rethink/index.htm

Gann, D.M., 'Construction as a manufacturing process? Similarities and differences between industrialised housing and car production in Japan', Construction Management and Economics (1996), 14,pp.437-450.

Hohlsiepe, U., and Breitmar, R.,'Lightweight building elements for residential housing', Steel Times, May 2000.

Howe, S.A., 'Kit-of-parts: A Review of ObjectOriented Construction Techniques', $16^{\text {th }}$ International Symposium on Automation and Robotics in Construction, Madrid, Sept. 1999. pp.165-171.

Wise, C.,' People: structure: engineering - standing on the shoulders of giants', The Structural Engineer, Vol 78/No.1, Jan 2000. 